\title{
Peningkatan produksi petani Jamur Tiram dengan teknik kultur di Kota Medan
}

\author{
Yurnaliza, Liana Dwi Sri Hastuti*, Riyanto Sinaga, Adrian Hartanto, \& Wita E Tarigan \\ Universitas Sumatera Utara \\ *liana.hastuti@usu.ac.id
}

\begin{abstract}
Abstrak. Jamur tiram merupakan salah satu komoditas yang sedang diminati masyarakat untuk memenuhi kebutuhan makanan sehat dan bergizi, dimana permintaan yang terus meningkat setiap tahunnya. Di kota Medan sendiri budidaya jamur tiram sudah mulai berkembang, baik skala industri rumah tangga maupun skala kecil hingga menengah namun belum memenuhi permintaan pasar. Salah satu yang menyebabkan rendahnya produksi jamur tiram adalah ketersediaan bibit, baik F-0, F-1, F-2 maupun F-3 sehingga petani gagal untuk dapat membuat media baglog sebagai tahap akhir dalam produksi jamur tiram. Bibit serta baglog dapat diproduksi sendiri oleh petani, jika dalam pembuatannya sesuai dengan standar kultur teknik dalam produksi bibit. Sosialisasi telah dilakukan dengan metode penyuluhan, demonstrasi dan mengintroduksi teknologi kultur serta sterilisasi dengan menggunakan autoklaf hemat energi sesuai kepada kebutuhan petani jamur. Penggunaan autoklaf sangat efektif dan signifikan dalam menurunkan jumlah bibit yang terkontaminasi, terlihat pada grafik yang turut ditampilkan pada tulisan ini. Pengetahuan membuat tepung jamur dengan metode sederhana dengan cost rendah dalam kemasan kekinian serta higienis siap dipasarkan sebagai bahan dasar produk olahan makanan atau sebagai bahan obat tradisional juga diberikan.
\end{abstract}

Kata kunci: jamur tiram, Medan, autoklaf, tepung jamur

\begin{abstract}
Oyster mushrooms are one of the commodities that people are interested in to meet the needs of healthy and nutritious foods, where the demand of this fungus increases every year. In the city of Medan, oyster mushroom cultivation has begun to develop in the home industry, small to medium scale industries, but in fact it has not yet fulfilled the market demand. The low production of oyster mushrooms caused by the low knowledge of the farmer in preparation of the seed, either F-0, F-1, F-2 or F-3 and ultimately fail in baglog preparation as the final media stage for oyster mushroom production. In the seedlings and backlogs manufacturer should follow the technical culture standard preparation of seedling. Socialization has been carried out by Tim ABDIMAS with the demonstration and introducing culture and sterilization technique using saving energy autoclave, efficient in use for the mushroom farmers and expected after the program the farmers can be confident and become independent in spawn or seedling producing by themselves. The use of autoclave is very effective and significant in reducing the number of contaminated seedlings, as seen in the graph which is also presented in this paper. Knowledge of making mushroom flour with a simple method with low cost in contemporary and hygienic packaging ready to be marketed as a basic ingredient in food processed products or as an ingredient in traditional medicine is also provided.
\end{abstract}

Keywords: oyster mushrooms, Medan, autoclave, mushroom flour

To cite this article: Yurnaliza., L. D. S. Hastuti., R. Sinaga., A. Hartanto., \& W. E. Tarigan. 2020. Peningkatan produksi petani Jamur Tiram dengan teknik kultur di Kota Medan. Unri Conference Series: Community Engagement 2: 335-343. https://doi.org/10.31258/unricsce.2.335-343

(c) 2020 Authors

Peer-review under responsibility of the organizing committee of Seminar Nasional Pemberdayaan Masyarakat 2020 


\section{PENDAHULUAN}

Jamur tiram merupakan salah satu komoditas yang sedang diminati masyarakat untuk memenuhi kebutuhan pangan. Hal ini dapat dilihat dari permintaan yang terus meningkat setiap tahunnya. Permintaan jamur tiram yang cukup tinggi masih belum terpenuhi, sehingga harus didatangkan dari luar daerah. Berbeda dengan ketersediaan jamur tiram di Pulau Jawa yang terpenuhi permintaanya karena jumlah petani jamur tiram yang banyak (Zulfiana et.al. 2013). Menurut Badan Pusat Statistik tahun 2017, tingkat konsumsi jamur di Indonesia Mencapai 47.753ton sedangkan produksinya hanya 37.020 ton. Setiap tahun permintaan jamur tiram meningkat $10 \%$ baik untuk kebutuhan hotel, restoran, vegetarian dan lain sebagainya (Achmad, 2014)

Untuk mengatasi tingginya permintaan akan jamur tiram di pasar, maka dengan adanya bibit unggul yang berkualitas dalam penyediaan F-0, F-1, F-2 dan Baglog, mampu memenuhi kebutuhan pasar, baik dalam bentuk produk segar maupun olahan. Selain bibit unggul, adanya alat-alat pembudidayaan jamur tiram seperti autoklaf, laminar air flow atau inkes, press baglog dan rak besi baglog yang sesuai standar untuk membantu memenuhi kegiatan produksi agar terjaminnya kestabilan pasokan jamur tiram terhadap permintaan (Azmi, 2014) Analisis dan manajemen pasar akan membantu dalam mendata kebutuhan pasar akan jamur tiram sehingga tidak ada pasar yang kekurangan pasokan jamur tiram. Dalam pengembangan strategi pemasaran, para petani jamur tiram dapat mengembangkan manajemen bisnis yang tepat dengan mengamati permintaan pasar dengan sistem pembukuan yang modern sehingga mampu menentukan metode operasi produksi yang tepat dalam upaya memenuhi kebutuhan pasar. Adanya sistem ini diharapkan para petani mampu menyeimbangi kebutuhan pasar yang terus meningkat setiap tahunnya.

Melalui program pengabdian kepada masyarakat ini diharapkan kelompok petani di daerah tersebut memiliki keterampilan menganalisis produksi dalam pemasaran jamur. Sehingga mampu menentukan metode persediaan yang baik untuk dijalankan sesuai dengan kondisi permintaan pasar. Agar tidak ada produksi yang berlebihan atau stok jamur yang sedikit.

\section{Analisis situasi}

Mikko Jamur merupakan salah satu usaha yang bergerak di bidang pertanian khususnya jamur tiram yang didirikan pada Februari 2019, terletak di tengah Kota Medan, beralamat di Jl. Sei Batang Hari, Gg. Abadi 126 H, Kelurahan Babura Sunggal, Kecamatan Medan Sunggal. Luas lahan usaha $320 \mathrm{~m} 2$ dengan kapasitas baglog jamur saat ini mencapai $2000 \log$ dalam kumbung yang berukuran $8 \times 3.5 \mathrm{~m} 2$. Mitra usaha ini dimiliki oleh Rakha Ajie Prabowo (alumni Biologi UNIMED) dan Iradani Yupita Ningrum (alumni Biologi USU).

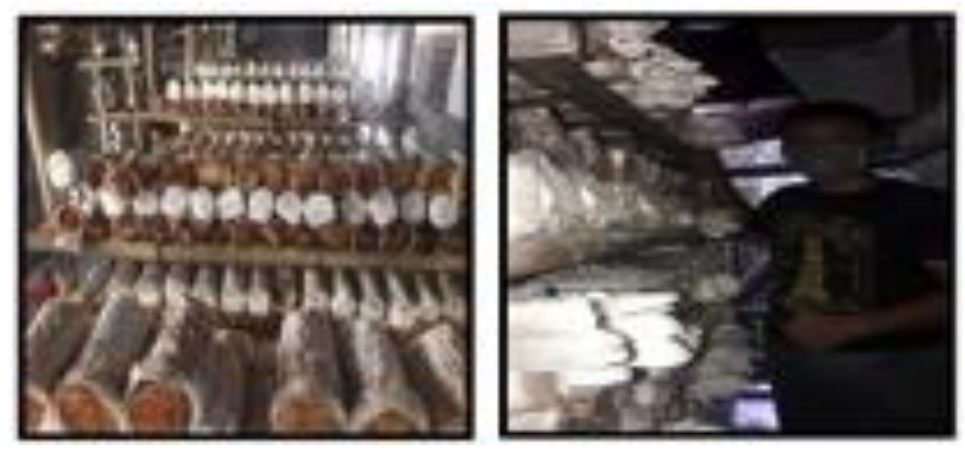

Gambar 1. Kumbung Jamur Tiram

Di dalam pembibitan jamur tiram dapat dilakukan dengan beberapa tahap yaitu F-0, F-1, F-2 dan baglog. Satu indukan dapat menghasilkan 6 botol F-0 dapat dikulturkan menjadi 150 botol F-1, dan 150 botol F-1 dapat dikulturkan menjadi 9000 botol F-2 dan 9000 botol F-2 dapat menghasilkan 270.000 botol F-3 atau baglog (Zulfiarna et.al. 2013).

Adapun alur kerja proses pembuatan bibit jamur tiram, diawali dengan pembuatan bibit F-0, dikulturkan menjadi F-1, dikulturkan menjadi F-2, dikulturkan lagi hingga F-3 atau baglog, hingga jamur tiram mencapai masa panen. Media yang biasa digunakan untuk pembuatan bibit F-0 adalah media Potato Dextrose Agar (PDA) yang dapat dibuat secara sederhana dengan bahan-bahan yang tersedia disekitar kita, yaitu tepung agar, gula dan ekstrak kentang Untuk bibit F-1, F-2 dan seterusnya biasa digunakan jagung pipil (Corn cob) atau bulir padi, dan bekatul. Untuk media baglog digunakan bahan, yaitu limbah serbuk kayu yang dicampur dengan dedak dan kapur (Kalsum, 2011). 
Tetapi pada umumnya petani hanya membeli baglog siap panen yang sudah berisi miselium jamur tiram. $\mathrm{Hal}$ ini disebabkan karena sebagian petani belum memiliki alat dan prasarana produksi yang standar. Dalam hal ini, mitra termasuk mengalami kendala tersebut, seperti ruang pembibitan yang belum memadai, alat yang masih cenderung sederhana, sehingga menjadi kendala dalam produksi jamur tiram pada mitra.
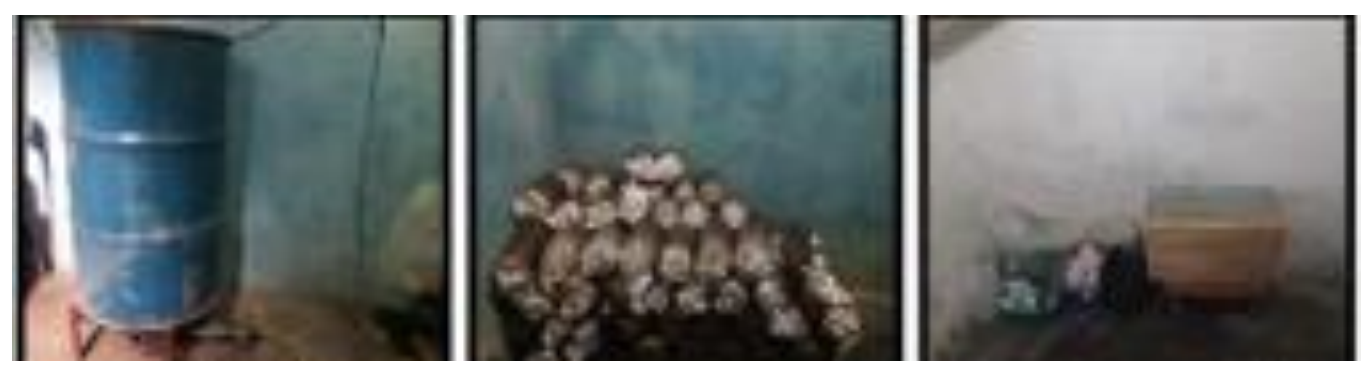

Gambar 2. Situasi ruang produksi mitra

Untuk saat ini mitra memproduksi jamur tiram masih menggunakan alat dan prasarana yang sederhana dan dilakukan oleh mitra sendiri. Untuk memproduksi baglog diawali dengan pengaduk baglog yang dilakukan sendiri (belum memakai tenaga kerja). Untuk alat sterilisasi digunakan drum bekas yang berkapasitas 65 baglog dilengkapi dengan pembakaran satu tungku menggunakan gas berukuran $3 \mathrm{~kg}$. Selanjutnya dalam pembibitan seperti F-1, F-2 dilakukan di ruangan berukuran $3 \times 3 \mathrm{~m}^{2}$. Untuk pengisian baglog dilakukan sendiri di ruangan berukuran $4 \times 3 \mathrm{~m} 2$. Sedangkan untuk proses inkubasi dilakukan di ruangan berukuran $4 \times 2 \mathrm{~m}^{2}$. Usaha jamur tiram tidak menimbulkan kerusakan pada lingkungan dan dapat mengurangi limbah. Pembuatan media tanam jamur tiram terdiri dari serbuk kayu gergaji yang merupakan limbah dari pengrajin kayu dan bekatul sebagai nutrisi serta kapur atau dolomit untuk mengatur pH media (Karisman, 2015).

\section{Permasalahan mitra}

Jamur tiram yang dikembangkan mitra di tengah Kota Medan, beralamat di Jl. Sei Batang Hari, Gg. Abadi 126 H, Kelurahan Babura Sunggal, Kecamatan Medan Sunggal. Memiliki pasar di daerah sekitar Kelurahan Babura. Mitra memiliki segmen pasar di pedagang kaki lima (PKL) jamur krispi, buyer jamur tiram ke restoran, pasar tradisional dan pembelian secara online.

Namun dari segi penjualan di pasar, pemenuhan jamur tiram masih fluktuatif. Hal ini mungkin dipengaruhi oleh beberapa faktor antara lain permintaannya yang lebih tinggi dibandingkan dengan produksi yang dihasilkan oleh para produsen jamur tiram di Kelurahan Babura Sunggal. Menurut (Mitha, 2015), faktor lain yang terkait adalah jumlah baglog yang masih minim akibat produksi yang belum maksimal. Aspek ini perlu dianalisa untuk mendalami lebih lanjut terkait tingkat produksi dan pemenuhan kebutuhan pasar. Selain itu, daya simpan jamur tiram setelah panen tidak tahan lama sehingga harus segera dipasarkan.

Menurut (Nurghara, 2006) dalam melakukan analisis terhadap aspek pasar dan pemasaran perlu diadakan pengembangan terhadap beberapa hal yang perlu diperhatikan yaitu permintaan, proyeksi permintaan dan penawaran, proyeksi penjualan, produk (barang/jasa), segmentasi pasar, strategi dan implementasi pemasaran.

Tingkat penjualan para pedagang jamur tiram yang ada di pasar baik pasar tradisional maupun supermarket hanya bergantung dari para pengusaha jamur yang masih terbatas jumlahnya. Pada hari Senin sampai dengan Sabtu permintaan jamur tiram lebih tinggi daripada hari Minggu. Biasanya juga produsen jamur cenderung lebih banyak memasok jamur ke pedagang pada akhir minggu hal ini disebabkan pada akhir minggu biasanya jumlah pembeli atau konsumen lebih banyak dikarenakan mereka memiliki kesempatan untuk berbelanja di pasar, selain itu banyak acara-acara keluarga yang juga mendorong permintaan jamur lebih tinggi dari hari biasa (Piryadi, 2013). Hal ini sejalan dengan penelitian yang dilakukan oleh (Satrianto, 2013) yang menyatakan bahwa di akhir pekan pasokan jamur lebih banyak dari pada hari biasa. Jamur yang di jual pada pedagang dipasar habis terjual sehingga jika diasumsikan jamur yang dijual dipasaran hanya memenuhi sekitar $25 \%$ permintaan konsumen maka permintaan jamur tiram per hari diperkirakan mencapai $300 \mathrm{~kg}$ per harinya. Kasus tersebut berbeda dengan yang dialami oleh mitra. Permintaan tertinggi pada hari Senin hingga Sabtu, sedangkan menurun pada hari Minggu. Hal ini dikarenakan pasokan jamur tiram ke pelanggan terbanyak pada pedagang krispi yang segmen pasarnya berada di sekolah. 
Selain itu perkembangan harga jamur tiram melonjak setiap memasuki bulan Ramadhan (Mei-Agustus). Harga jamur tiram dari produsen ke pengumpul pada tahun 2014 melonjak dari Rp 10.000,00/kg menjadi $\mathrm{Rp} 12.000,00 / \mathrm{kg}$ dan harga dari pengepul ke konsumen naik dari Rp 13.000,00/kg menjadi Rp18.000,00/kg (Soenanto, 2000). Sejalan dengan penelitian yang dilakukan oleh (Suharjo, 2013) yakni di dapati permintaan jamur tiram pada Tahun 2005 permintaan pedagang jamur kepada para produsen jamur masih belum dapat dipenuhi sehingga hal ini menunjukkan bahwa sebenarnya daya serap pasar masih lebih besar dari pada tingkat produksi yang dihasilkan produsen, pada Tahun tersebut permintaan yang belum dipenuhi sekitar 50-100 kg untuk setiap pasar perhari.

Menurut (Suharnowo, 2012) pemberdayaan masyarakat atau pengabdian merupakan suatu kegigihan dan kemampuan masyarakat dalam mensejahterakan keluarga mereka. Pengabdian yang dilakukan yaitu budidaya dan pengolahan produk jamur tiram. Prospek budidaya jamur tiram sangat menjanjikan jika kualitas dan kuantitas produk sesuai dengan persyaratan. Mengamati keadaan ini tentunya analisis data untuk strategi pemasaran perlu dilakukan. Sehingga berdampak pada prospek usaha tani jamur tiram sebagai sesuatu yang menjanjikan dalam menghadapi lonjakan-lonjakan permintaan pasar pada kondisi-kondisi tertentu. Produksi ditingkatkan sesuai dengan permintaan konsumsi masyarakat. Keadaan ini berdampak positif bagi kemajuan perkembangan usaha tani jamur tiram.

\section{METODE PENERAPAN}

Dalam meningkatkan produksi mitra, mulai dari pembibitan sampai hasil panen jamur tiram, perlu dilakukan pengadaan alat produksi yang memadai guna tercapainya produksi sesuai standar. Adanya alat produksi yang terbarukan, untuk proses pembibitan, mendapatkan peluang keberhasilan yang tinggi, maka produksi baglog yang awalnya hanya menghasilkan 50 baglog per hari menjadi 300 baglog per hari sehingga untuk menuruti permintaan jamur tiram segar terhadap pasar akan stabil bahkan menaikkan omzet, karena ketersedian baglog yang seimbang untuk dipasok ke kumbung jamur. Dampak dari meningkatnya produksi ini adalah membuka lapangan kerja bagi warga sekitar lokasi usaha mitra, karena dengan produksi yang harus mencapai target diperlukan sumber daya manusia sebagai tenaga kerja yang akan membantu dalam mencapai target produksi tersebut. Berdasarkan permasalahan yang telah dikemukakan di atas, maka dalam kegiatan pengabdian masyarakat ini menggunakan metode pendekatan sosialisasi (penyuluhan), pelatihan manajemen usaha, penggunaan alat dan pendampingan.

Dari permasalahan yang ada maka untuk mencapai tujuan yang diharapkan, metode pendekatan yang ditawarkan untuk mengatasi masalah tersebut secara operasional adalah sebagai berikut:

\section{a. Standarisasi Pembuatan Bibit}

Sterilisasi ruangan pembibitan dilakukan dengan cara mensterilkan alat-alat inokulasi bibit jamur tiram dan tangan dengan cara menyemprotkan alkohol 70\% serta bahan media menggunakan autoklaf. Proses inokulasi bibit F0 dilakukan dengan cara aseptis dengan memotong bagian tubuh buah indukan jamur tiram di posisi belakang dengan ciri bentuk yang membengkak. Potongan tubuh buah jamur diinokulasikan ke dalam media PDA dan diinkubasi selama kurang lebih 14 hari. Setelah seluruh miselium memenuhi media, dilakukan inokulasi ke media selanjutnya yang disebut F-1 dengan cara memotong agar. Hal ini dilakukan sampai didapatkan F-2. Kemudian dilanjutkan dengan menginokulasikan F-2 ke media baglog. Merancang ruang kerja yang lebih steril sehingga dapat melakukan pembuatan bibit secara aseptis seperti, memisahkan antara ruang pembibitan, ruang inokulasi, ruang inkubasi dan ruang produksi media tanam (baglog). Menyiapkan bahan baku dan peralatan sederhana untuk dapat bekerja sesuai sistem standar, termasuk memperkecil permasalahan limbah. Dengan memberikan kepada petani alat sterilisasi uap panas (Autoklaf) dengan tekanan 2 atm suhu $121^{\circ} \mathrm{C}$ dan volume $300 \mathrm{~L}$, laminar/inkes untuk membuat bibit F-0, F-1 dan F2 yang aseptis serta rak besi inkubasi baglog yang mampu menampung hingga 5.000 - 10.000 baglog dan awet hingga kurang lebih 6 tahun.

\section{b. Manajemen Produksi Baglog dan Kumbung}

Pembuatan baglog diawali dengan membuat media yang terdiri dari serbuk kayu, dedak dan kapur dengan perbandingan 100:10:1, ditambah air dengan kadar 60\%. Pengadukan baglog dilakukan dengan cara manual dengan menggunakan sekop. Media yang sudah homogen difermentasi selama 1-2 hari. setelah proses fermentasi selesai, media dimasukan kedalam plastik jenis polypropylene (PP) dengan ukuran 18 x $35 \mathrm{~cm}$. Lalu media dipadatkan menggunakan press baglog. Tahap akhir yaitu, baglog yang sudah dipadatkan dan ditutup dengan cincin, dikukus menggunakan steamer manual (drum) selama 3 jam dengan suhu $100^{\circ} \mathrm{C}$. Setelah melalui proses pengukusan, baglog dibiarkan semalaman. Diinokulasikan bibit F-2 ke dalam baglog 
secara aseptis dan disimpan di ruang inkubasi selama 40 hari. hasil inkubasi baglog dibawa ke dalam kumbung untuk menumbuhkan bakal jamur. Syarat kumbung agar jamur tumbuh optimal, adalah keadaan kumbung haruslh sejuk dn lembab dengan sirkulasi udara yang teratur. Dalam hal ini pengaturan tinggi atap dari bangunan kumbung sangat diperhatikan, seperti tinggi bangunan $3 \mathrm{~m}$ dan jarak antara bangunan dengan atap adalah 3-4 m agar menjaga sirkulasi udara tetap stabil apabila musim panas.

Tabel 1. Metode Pelaksanaan

\begin{tabular}{llccl}
\hline No & Aplikasi Kegiatan & Metode Pendekatan & Target & \multicolumn{1}{c}{ Partisipasi Mitra } \\
\hline 1. & Analisis kebutuhan. & Penyuluhan. & $\begin{array}{c}\text { Mitra sebagai } \\
\text { produsen. }\end{array}$ & $\begin{array}{l}\text { Hadir dalam penyuluhan dan aktif } \\
\text { dalam tanya jawab. }\end{array}$ \\
& $\begin{array}{l}\text { Memaparkan } \\
\text { tentang metode } \\
\text { persediaan yang } \\
\text { baik. }\end{array}$ & Sosialisasi. & $\begin{array}{c}\text { Mitra (Pemilik, } \\
\text { Manajemen dan } \\
\text { Pekerja). }\end{array}$ & $\begin{array}{l}\text { Mengikuti konsep sosialisasi } \\
\text { memberi kesempatan kepada } \\
\text { setiap pekerja untuk } \\
\text { mengembangkan diri dalam } \\
\text { menunjang pengembangan usaha }\end{array}$ \\
& & Sosialisasi dan \\
Aplikasi. & $\begin{array}{c}\text { Mitra (Pemilik, } \\
\text { Manajemen dan } \\
\text { Pekerja). }\end{array}$ & $\begin{array}{l}\text { Bersedia mengikuti konsep } \\
\text { sosialisasi,aktif dalam tanya } \\
\text { jawab }\end{array}$ \\
\hline
\end{tabular}

\section{HASIL DAN KETERCAPAIAN SASARAN}

Pengabdian masyarakat ini menerapkan inovasi teknologi tepat guna kepada petani jamur tiram. Dimana alat yang diberikan berupa sebuah teknologi yang bisa digunakan oleh petani dalam keseharian. Adapun hasil dari pengabdian ini adalah:

\section{Renovasi Ruangan Pembuatan Bibit Jamur Tiram}

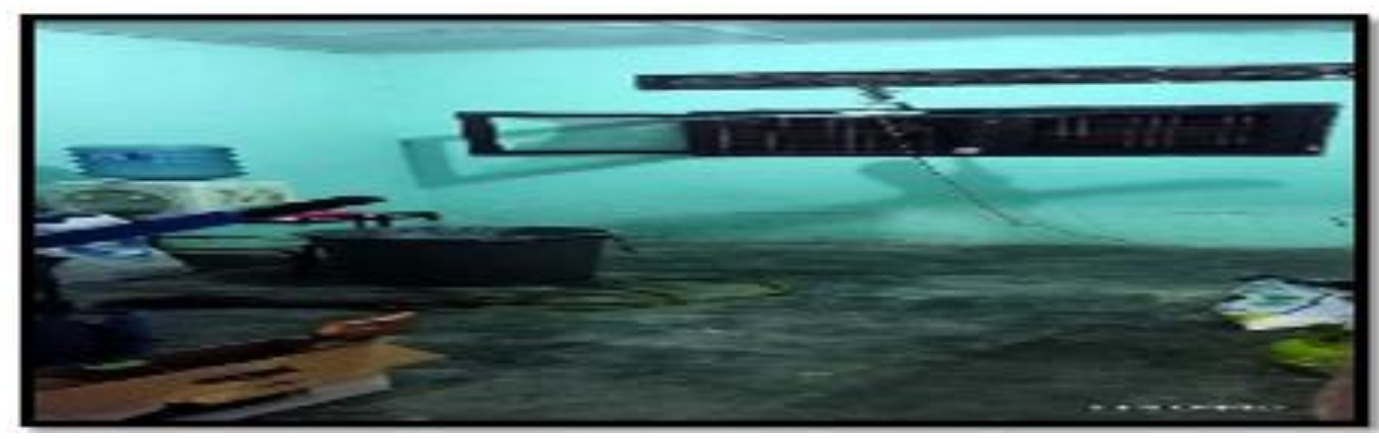

Gambar 3. Ruangan Sebelum Direnovasi

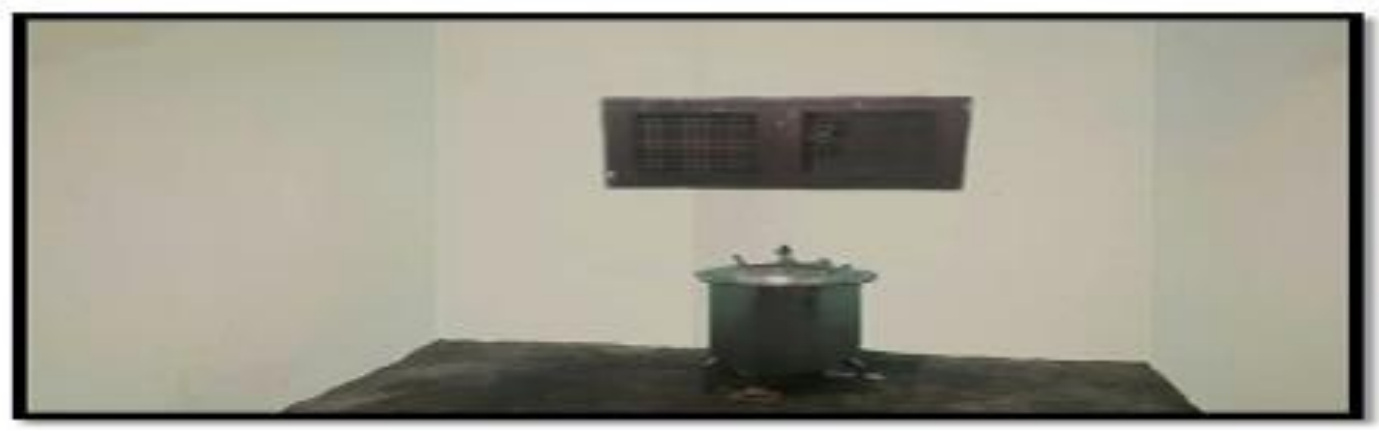

Gambar 4. Ruangan Sesudah Direnovasi 
Gambar 3 menunjukkan kondisi ruang pembibitan masih dalam kondisi yang kurang steril dan masih belum tertata rapi. Hal ini dapat menyebabkan mudah terjadinya kontaminasi saat pembibitan jamur tiram. Gambar 4 menunjukkan kondisi ruang pembibitan yang sudah dalam kondisi lebih baik dan steril sehingga proses pembibitan jamur lebih baik dan terjadinya kontaminasi lebih sedikit.

\section{Pemberian Autoklaf kepada Petani Jamur Tiram}
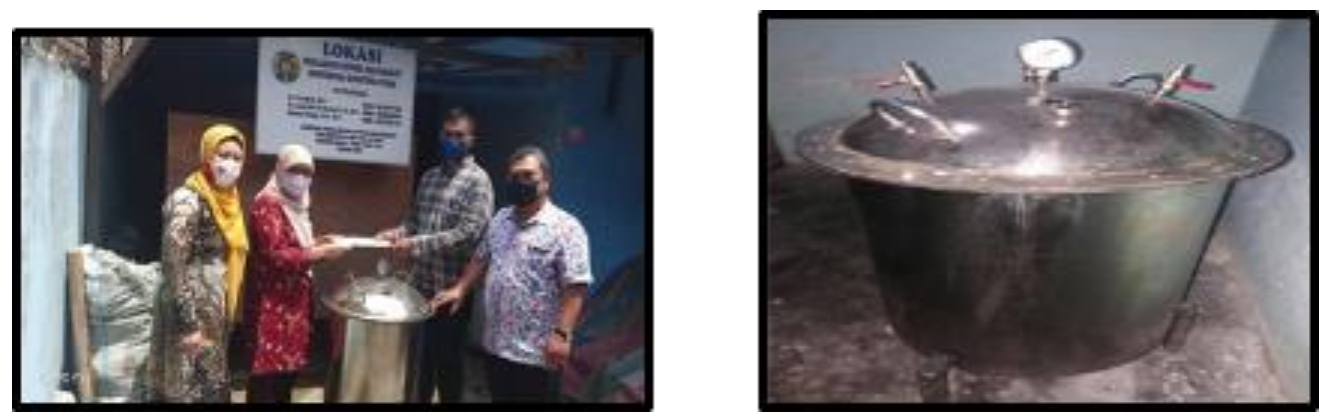

Gambar 5. Pemberian autoklaf pada petani jamur

Pemberian autoklaf diserahkan oleh Tim pengabdian kepada petani jamur milenial Rakha Ajie Prabowo. Pemberian autoklaf ini bertujuan untuk meningkatkan produksi bibit jamur tiram dan menjadikan petani lebih mandiri tanpa bergantung kepada produsen jamur tiram lain.

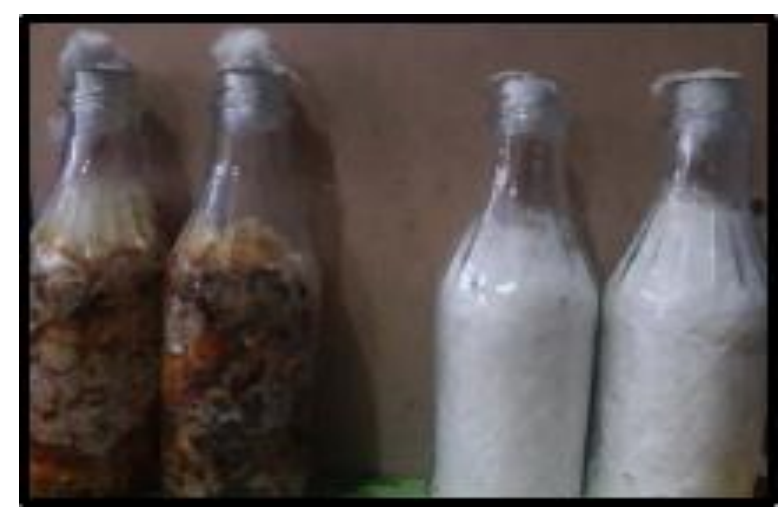

Gambar 6. Bibit F1 dan F2 sesudah dan sebelum menggunakan autoklaf

Pemberian autoklaf pada petani jamur diharapkan dapat meminimalisir terjadinya kegagalan pada saat pembuatan bibit F0, F1 dan F2 yang sering terkontaminasi, sehingga produksi jamur tiram akan meningkat. Hal ini dapat dilihat dari tingkat keberhasilan bibit. Dimana sebelum menggunakan autoklaf, tingkat keberhasilan bibit sebesar 0\%. Sedangkan setelah menggunakan autoklaf, tingkat keberhasilan bibit sebesar $100 \%$. 


\section{Sosialisasi Pengerjaan Bibit Jamur yang Benar dan Steril}

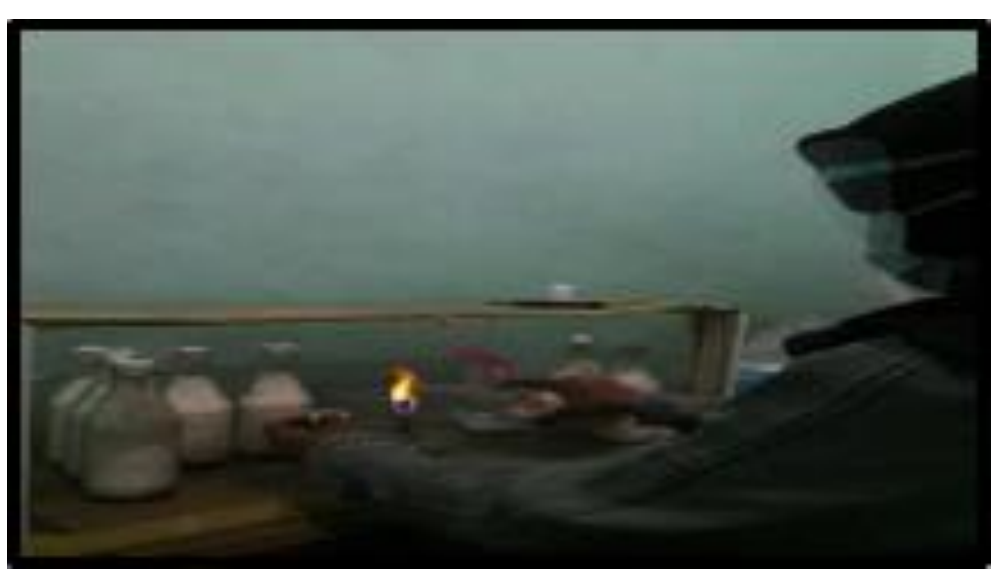

Gambar 7. Pembibitan F1 dan F2 secara aseptis

Gambar 7 menunjukkan sebelum melakukan pembibitan hal yang harus dilakukan yaitu dengan mensterilkan ruangan yang dipakai dengan alkohol $70 \%$ dan memakai sarung tangan sebelum memulai pengerjaan. Cara memegang cawan petri yang benar agar tetap steril saat akan membuat bibit F0, dimana cawan petri berada diatas nyala api Bunsen, cawan diputar-putar hingga terasa panas, setelah itu bibit jamur tiram segar bias dimasukkan ke dalam cawan petri. Gambar 7 menunjukkan cara memegang botol bibit F3 yang akan dimasukkan ke dalam baglog agar kondisi tetap steril, dimana botol berada diatas nyala api bunsen agar kondisi steril tetap terjaga dan mencegah terjadinya kontaminasi.

\section{Olahan Jamur Tiram menjadi Tepung Jamur}

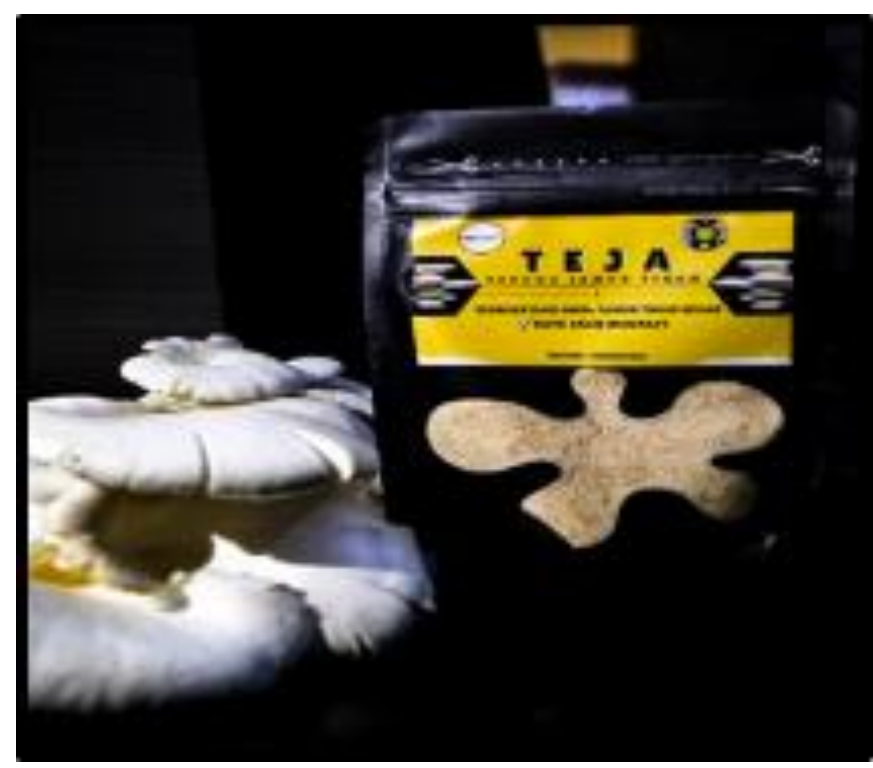

Gambar 8. Produk olahan berupa tepung jamur tiram

Gambar 8 menunjukkan mitra melakukan pengolahan terhadap jamur tiram apabila mengalami panen membludak. Hal ini merupakan salah satu solusi yang tepat untuk menanggulangi kerugian akibat membludaknya panen jamur tiram. Sehingga dimanfaatkan oleh mitra menjadi tepung jamur 


\section{Pembentukan Komunitas Petani Jamur Tiram di Kota Medan}

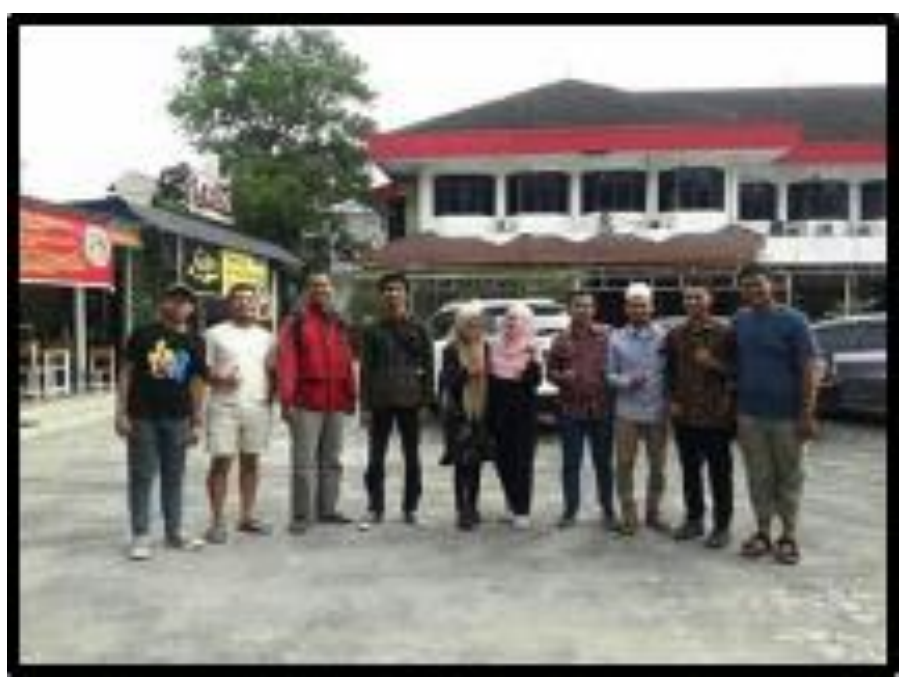

Gambar 9. Pembentukan komunitas para petani jamur tiram di kota Medan

Pada bulan Juni 2020, pembentukan komunitas petani jamur Medan dengan nama Rumah Jamur Medan telah resmi dibentuk. Pembentukan ini bertujuan untuk menampung aspirasi petani jamur tiram, mengatasi pasca panen, pembentukan koperasi dan menjadi ikon di kota Medan.

\section{Hasil Efektifitas Penggunaan Alat Sterilisasi}
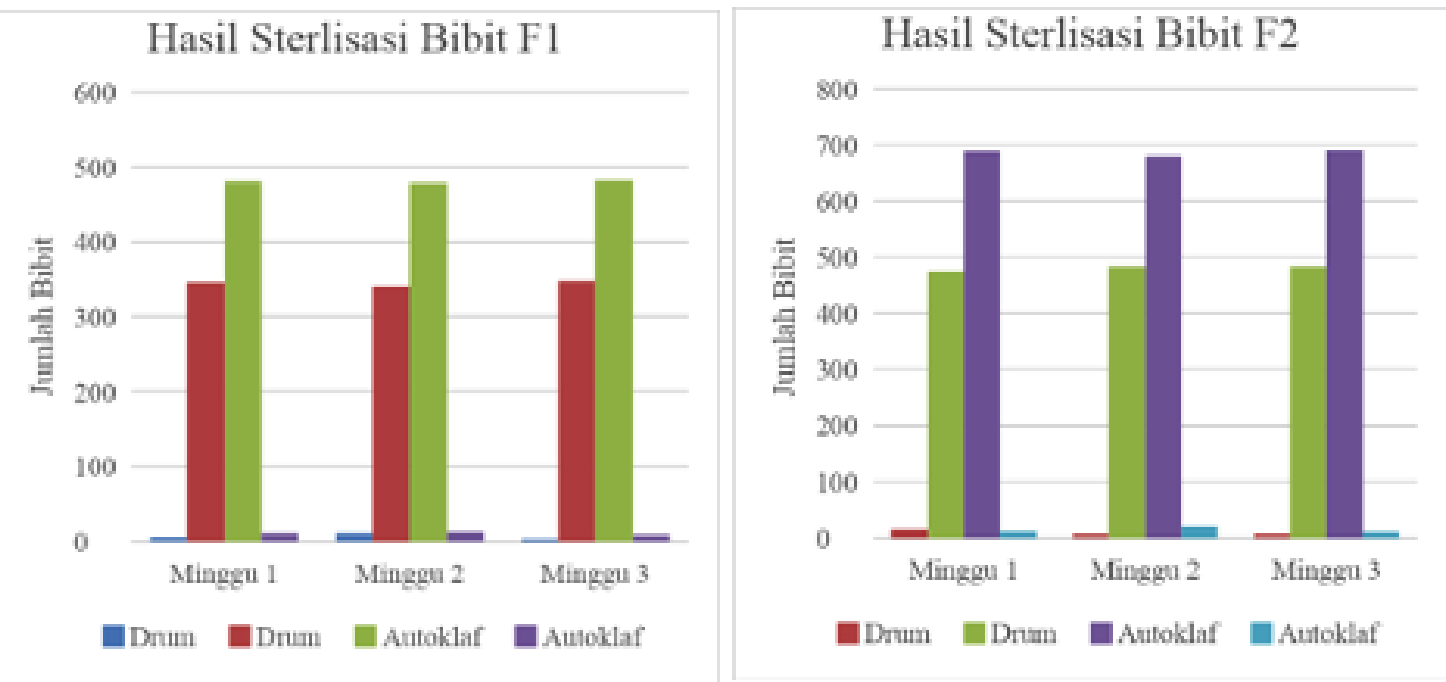

Gambar 10. Hasil Efektivitas Sterilisasi a) Bibit Jamur F1 b) Bibit Jamur F2

Dari Gambar 10 dan 11 menunjukkan dari hasil penggunaan sterilisasi bibit jamur yaitu bibit F1 dan F2 di lokasi pengabdian ini menunjukkan penggunaan alat sterilisasi yaitu autoklaf sangat menambah jumlah produksi bibit yang lebih banyak dibandingkan menggunakan yaitu drum. Tingkat keberhasilan penggunaan autoklaf sangat besar dilihat dari jumlah jamur yang dihasilkan dibandingkan drum yang tingkat keberhasilan yang sangat kecil. Sejalan dengan menurut pendapat (Ravikrishna, 2013) Sterilisasi adalah istilah yang mengacu pada setiap proses yang menghilangkan atau membunuh semua bentuk kehidupan mikroba seperti jamur, bakteri, bentuk spora, dll., Yang ada di permukaan, terkandung dalam cairan, dalam pengobatan, atau dalam suatu senyawa seperti media kultur. Penggunaan alat sterilisasi sangat penting dalam meningkatkan hasil kultur bibit jamur. 


\section{KESIMPULAN}

Penggunaan autoklaf serta teknik inokulasi bibit sesuai standar operasional terbukti menghasilkan bibit yang baik dan tidak terkontaminasi. Petani juga diberikan suatu pengetahuan membuat produk berupa tepung jamur yang siap dipasarkan sebagai bahan dasar produk olahan makanan atau sebagai obat tradisional. Petani juga mendapatkan pelatihan bagaimana membuat kemasan yang lebih kekinian, menarik pelanggan serta higienis. Metode sederhana dalam pembuatan tepung telah diberikan sehingga petani mampu memproduksi dengan biaya produksi yang relatif rendah, sehingga dapat dipasarkan dengan harga terjangkau masyarakat

\section{UCAPAN TERIMA KASIH}

Penulis mengucapkan terimakasih kepada Lembaga Pengabdian Pada Masyarakat (LPPM) Universitas Sumatera Utara yang telah memberikan dukungan pendanaan selama berlangsungnya program mono tahun reguler tahun 2020 Ini.

\section{DAFTAR PUSTAKA}

Achmad., M., Arlianti, T., Azmi, C. 2011. Panduan Lengkap Jamur. Jakarta. Penebar Swadaya.

Azmi N. dan Hidayati R. 2014. Analisis Tingkat Permintaan Jamur Tiram di Pasar Tradisional dan Supermarket di Kota Palembang. Jurnal Ilmiah AgrIBA, 2, 169-176.

Kalsum, U., Siti F, dan Catur W. 2011. Efektivitas Pemberian Air Leri terhadap Pertumbuhan dan Hasil Jamur Tiram Putih (Pleurotus ostreatus). Agrovigor, 4(2), 86-92.

Karisman, W. 2015. Pengaruh Perbandingan Limbah Serbuk Kayu dan Blotong terhadap Produksi Jamur Tiram Putih (Pleurotus ostreatus). Prosiding Seminar Nasional Pendidikan Biologi. UMM Malang.

Mitha SD. 2015. Analisis Pendapatan dan Kesejahteraan Produsen Jamur Tiram di Kota Metro. Jurnal Ilmu-Ilmu Agribisnis, 3(2), 140-147

Nugraha AP. 2006. Analisis Efisiensi Saluran Pemasaran Jamur Tiram Segar di Bogor Provinsi Jawa Barat. Skripsi. Fakultas Pertanian Program Studi Manajemen Agribisnis Institut Pertanian Bogor. Bogor.

Priyadi TU. 2013. Bisnis Jamur Tiram. PT. Agro Media Pustaka. Jakarta.

Ravikrishna S, 2013. Practical guide to safe Autoclaving. International Journal of Scientific \& Engineering Research, 4(6), 3020-3026.

Satrianto, F. 2013. Multiplikasi dalam Pembibitan Jamur Tiram. Malang: Karya Jamur Persada

Soenanto, H. 2000. Jamur Tiram Budidaya dan Peluang Usaha. Aneka Ilmu. Semarang

Suharjo, E. 2015. Budi Daya Jamur Tiram Media Kardus. AgroMedia Pustaka. Jakarta Selatan.

Suharnowo, L. S., Budipramana dan Isnawati. 2012. Pertumbuhan Miselium dan Produksi Tubuh Buah Jamur Tiram Putih (Pleurotus ostreatus) dengan Memanfaatkan Kulit Ari Biji Kedelai Sebagai Campuran pada Media Tanam. Lenterabio, 4(1), 125-130

Zulfarina, S E., Yustina, Putra, R. A., dan Suharnowo, H. T. 2019. Budidaya Jamur Tiram dan Olahannya untuk Kemandirian Masyarakat. Jurnal Pengabdian Kepada Masyarakat, 5(3), 358-370. 